\title{
ADOPSI E-COMMERCE OLEH KONSUMEN MILENIAL PADA PRODUK UMKM DI KOTA SUBANG MENGGUNAKAN MODEL UTAUT IN CONSUMER CONTEX
}

\author{
Rian Piarna*1, Ferdi Fathurohman ${ }^{2}$ \\ 1,2Politeknik Negeri Subang \\ Email: ${ }^{1}$ piarna@polsub.ac.id, ${ }^{2}$ ferdifathurohman@polsub.ac.id \\ *Penulis Korespondensi
}

(Naskah masuk: 30 Oktober 2019, diterima untuk diterbitkan: 07 Oktober 2020)

\begin{abstract}
Abstrak
Penelitian ini berfokus pada konsumen milenial yang melakukan belanja online produk UMKM pada ecommerce. Konsumen milenial yang semakin meningkat menjadi peluang bagi UMKM dalam target pemasaran dengan mengetahui bagaimana perilaku dalam berbelanja online. Penelitian ini bertujuan untuk mengkonfirmasi adanya hubungan positif dan signifikan antara (1) performance expectancy, (2) effort expectancy, (3) social influence, (4) facilitating condition, (5) hedonic motivation, (6) price value dan (7) habit terhadap behavioral intention. Adanya hubungan positif dan signifikan antara (8) facilitating condition dan (9) habit terhadap use behavior. Serta hubungan positif dan signifikan antara (10) behavioral intention berpengaruh signifikan terhadap use behavior. Pada hasil penelitian juga khusus melihat bagaimana usia sebagai variabel moderator mempengaruhi dalam adopsi penggunaan e-commerce. Metode pada penelitian ini menerapkan model Unified Theory of Acceptance and Use of Technology (UTAUT) yang berfokus pada perilaku konsumen. Sampel dalam penelitian ini sebanyak 150 responden milenial. Pengolahan data menggunakan SMART PLS. Hasilnya menunjukkan bahwa ada hubungan positif dan signifikan anatara social influence dan habit terhadap behavioral intenion. Ada hubungan positif dan signifikan anatara facilitating condition dan habit terhadap use behavior. Serta Ada hubungan positif dan signifikan pada behavioral intention terhadap use behavior. Hasil ini bisa menjadi referensi pelaku UMKM untuk mengembangkan pemasaran dengan mengggunakan media sosial karena konsumen milenial memiliki fasilitas untuk mengakses internet dalam aktifitasnya serta mudah dipengaruhi oleh lingkungan sosialnya.
\end{abstract}

Kata kunci: e-commerce, milenial, UMKM, UTAUT2

\section{E-COMMERCE ADOPTION BY MILLENIAL CONSUMERS ON UMKM PRODUCTS IN SUBANG CITY USING UTAUT MODEL IN CONSUMER CONTEX}

\begin{abstract}
This research focuses on millennial consumers who shop online for MSMEs products on e-commerce. Millennial consumers are increasingly becoming an opportunity for MSMEs in marketing targets by knowing how to behave online shopping. This study aims to confirm the existence of a positive and significant relationship between (1) performance expectancy, (2) effort expectancy, (3) social influence, (4) facilitating conditions, (5) hedonic motivation, (6) price value and (7) habit of behavioral intention. There is a positive and significant relationship between (8) facilitating conditions and (9) habits on use behavior. And a positive and significant relationship between (10) behavioral intention has a significant effect on use behavior. The research also specifically looks at how age as a moderating variable influences adoption of e-commerce. The method in this study applies the Unified Theory of Acceptance and Use of Technology (UTAUT) model that focuses on consumer behavior. The sample in this study were 150 millennial respondents. Data processing using PLS SMART. The results show that there is a positive and significant relationship between social influence and habit on behavioral intention. There is a positive and significant relationship between facilitating conditions and habits on use behavior. And there is a positive and significant relationship between behavioral intention and use behavior. These results can be a reference for SMEs to develop marketing by using social media because millennial consumers have the facility to access the internet in their activities and are easily influenced by their social environment.
\end{abstract}

Keywords: e-commerce, milenial, UTAUT2, PLS-SEM 


\section{PENDAhUluan}

Salah satu pasar e-commerce (jual beli daring) potensial di Asia salahsatunya adalah Indonesia. Hal ini terlihat dari survei We Are Social 2018, sekitar $40 \%$ dari 132 juta pengguna internet membeli barang dan jasa melalui e-commerce (Saputra, 2018). Peningkatan pengguna internet semakin tumbuh dengan cepat di Indonesia dengan komposisi usia konsumen milenial diantara 19-34 tahun merupakan pengguna internet terbanyak sebesar $49,52 \%$ (Association of Indonesian Internet Service Providers, 2017).

Komposisi ini memperilhatkan bahwa konsumen milenial merupakan konsumen yang paling banyak menggunakan internet dalam aktifitasnya. Konsumen milenial menjadi isu penting pada perkembangan dunia digital dan media sosial menjadi ruang komunikasi bagi generasi ini (Aziz, 2016). Konsumen milenial pada 2020-2030 akan dinikmati Indonesia karena mendapatkan masa bonus demografi karena jumlah usia produktif akan lebih besar diabndingkan dengan jumlah usia non produktif (Kemenpppa, 2017). Kondisi itulah yang mendasari pemilihan konsumen milenial sebagai objek penelitian ini dalam melakukan adopsi pada $e$ commerce terhadap produk UMKM (Usaha Mikro Kecil dan Menengah) di Kota Subang dengan fokus penelitian terhadap tingkat adopsi e-commerce dalam berbelanja produk UMKM menggunakan metode Unified Theory of Acceptance and Use of Technology (UTAUT) in Consumer Contex.

UTAUT2 merupakan pengembangan konsep model UTAUT (Venkatesh, Thong, \& Xu, 2012) UTAUT2 menggambarkan bagaimana konsumen beradaptasi dengan teknologi. UTAUT adalah model teori penerimaan teknologi dibandingkan dengan model sebelumnya diantaranya (1) technology acceptance model (TAM), (2) the innovation diffusion theory (IDT), (3) the theory of reasoned action (TRA), (4) the theory of planned behavior (TPB), (5) the motivational model (MM), (6) a model of combining TAM and TPB (C-TAM-TPB), (7) the model of PC utilization (MPCU) dan (8) the social cognitive theory (SCT) dalam mengintegrasikan konstruksi seseorang atau organisasi dalam penerimaan teknologi baru (Winarko \& Mahadewi, 2013).

Teori UTAUT 2 atau UTAUT in Consumer Context merupakan pengembangan model dari yang menggambarkan bagaimana konsumen beradaptasi terhadap sebuah teknologi baru dengan fokus pada adopsi teknologi oleh konsumen, pada UTAUT 2 terdapat tambahan tiga variabel prediktor diantaranya hedonic motivation (HM), price value (PV), dan habit (H) (Kamal \& Azis, 2015) dan (Pertiwi \& Ariyanto, 2017) . Beberapa penelitian adopsi teknologi dengan metode UTAUT2 diantranya adopsi layanan uang elektronik (Ramdhani, Rachmawati, Sidiq, \& Prabowo, 2017), mobile payment (Pertiwi \& Ariyanto, 2017)
Sehingga tujuan penelitian ini untuk mengetahui bagaimana behavioral intention diartikan sebagai konsumen milenial di Kota Subang berminat menggunakan teknologi internet dan use behavior sebagai indikasi kebiasaan dalam menggunakan teknologi internet untuk berbelanja secara online pada e-commerce.

Menurut Profil Bisnis UMKM Bank Indonesia (Bank Indonesia, 2015). UMKM mempunyai karakter yang erat antara aktifitas usaha dan perilaku pengusahanya. Karakteristik seperti inilah yang menjadi ciri khusus dan menjadi pembeda antar pelaku usaha berdasarkan skala usahanya. Ada tiga jenis pengelompokan UMKM menurut Bank Dunia berdasarkan jumlah karyawannya yaitu; Kategori Usaha Mikro memiliki 10 orang karyawan. Kategori Usaha Kecil memiliki 30 orang karyawan. Kategori Usaha Menengah mencapai hingga 300 orang karyawan.

Berbelanja produk UMKM dengan menggunakan internet dinilai dengan tujuh variabel prediktor pada UTAUT in consumer contex menurut Venkatesh et al (2012) diantaranya adalah performance expectancy, effort expectancy, social influence dan facilitating condition. Serta tiga variabel tambahan yaitu hedonic motivation, price value dan habit.

Selain itu juga diharapkan bisa memberikan informasi yang komrehensif tentang perilaku konsumen milenial untuk digunakan pelaku UMKM dalam pembuatan strategi e-commerce yang efektif dan berdaya saing. Dimana kelemahan UMKM saat ini adalah kurangnya pemahaman terhadap teknologi dan pemasaran tradisional dari mulut ke mulut (Bram, 2017).

Pesatnya perkembangan internet berdampak pada berbagai pola hidup manusia. Dampak pada setiap manusia memiliki hasil yang berbeda-beda. Ada yang mampu beradaptasi ada juga yang masih harus mempelajari perkembangan internet. Bentuk dari perkembangan internet salah satunya adalah jual beli secara daring yang masih didominasi oleh perusahaan-perusahaan yang mempunyai kemampuan dalam penyediaan internet yang baik sebaliknya UMKM masih memiliki keterbatasan dalam kemampuan penggunaan internet (Kamal \& Azis, 2015).

Padahal UMKM memiliki kontribusi strategis pada pembangunan ekonomi nasional, pendistribusian produk lokal dan pemberdayaan sumber daya manusia. UMKM juga mampu bertahan dan berdiri kokoh ketika terjadi krisis pada tahun 1997-1998 (Bank Indonesia, 2015). Kominfo merilis bahwa $18 \%$ pelaku UMKM memiliki akses ke internet namun belum memanfaatkan untuk kegiatan transaksi(Kominfo, 2016).

E-Commerce adalah kegiatan penjualan, pembelian, dan pemasaran produk ataupun jasa dengan koneksi internet (Wong, 2013). Kegiatan bisnis secara online memiliki beberapa keuntungan 
diantaranya adalah; ketersediaan produk secara online sehingga produk yang diperjualbelikan bisa di diakses dalam waktu 24 jam oleh konsumen. Ecommerce juga memiliki jangkauan bisnis yang sangat luas, transaksi bisa dilakukan tanpa uang melibatkan penjual dan pembeli secara langsung ataupun fisik. Pembeli bisa djuga bisa dengan mudah melihat produk dengan cepat dan murah. Efisiensi waktu juga bisa dirasakan pembeli karena bisa mendapatkan kemudahan saat menelusuri etalase online dengan cepat. Keterbukaan diri saat berbelanja juga bisa lebih terjaga karena tidak terlihat oleh orang lain (Sulianta, 2012).

Peningkatan penggunaan internet di Indonesia mendorong kemunculan situs penjualan yang menyediakan sistem penjualan daring Costumer-toCostumer (C2C) dan telah siap digunakan serta dimanfaatkan dengan modal terjangkau salah satunya adalah Shoppe.co.id.

Shopee.co.id merupakan aplikasi C2C nomor satu dengan memberikan potongan ongkos kirim. Kehadiran situs e-marketplace seperti Shopee.co.id menjadikan pelaku UMKM bisa memaksimalkan aktifitas penjualan produknya. Upaya ini bisa dicapai pelaku UMKM untuk mengetahui siapa konsumennya dan bagaimana konsumen beradaptasi dengan proses penjualan daring.

Informasi tentang konsumen ini bisa menjadi kunci keberhasilan untuk dimanfaatkan strategi penjualan daring. Dengan mengenal kebiasaan konsumen dalam melakukan pembelanjaan daring, UMKM bisa menyesuaikan tampilan toko daringnya dan bagaimana menarik calon konsumen agar melakukan pembelian (Kamal \& Azis, 2015).

Konsumen milenial merupakan generasi yag dekat dengan internet. Internet bagi generasi milenial telah menjadi kebutuhan pokok. Generasi milenial mempunyai selera dan perilaku berbeda dalam melakukan pembelian dan cara mengkonsumsi produk atau layanan. Sehingga konsumen milenial menjadi target ideal untuk dunia digital marketing (Alvara Research Center, 2017).

Konsumen milenial berkarakter unik dan berbeda dibandingkan dengan generasi lainnya. Dilihat dari usia yang tergolong muda, generasi ini akan memiliki peranan yang penting pada 20 tahun mendatang. Generasi milenial juga merupakan generasi yang dekat dengan internet sehingga generasi milenial ini merupakan konsumen potensial pada pasar e-commerce Indonesia (Kamal \& Azis, 2015). Jenis produk UMKM yang akan diteliti berdasarkan 25 kategori produk shopee.co.id. Hal ini dilakukan agar mendapatkan yang lebih spesifik dan mengurangi ketajaman analisis.

Atas pemamparan latar belakang tersebut, penelitian ini bermaksud untuk melakukan pengujian tingkat pengaruh pada hipotesis berikut;

H1: Performance expectancy (PE) memiliki pengaruh signifikan pada behavioral intention (BI).
H2: Effort expectancy (EE) memiliki pengaruh signifikan pada behavioral intention (BI)

H3: Social influence (SI) memiliki pengaruh signifikan pada behavioral intenion (BI).

H4a: Facilitating condition (FC) memiliki pengaruh signifikan pada behavioral intention (BI).

H4b: Facilitating condition (FC) memiliki pengaruh signifikan pada use behavior (UB).

H5: Hedonic motivation (HM) memiliki pengaruh signifikan pada behavioral intention (BI).

H6: Price value (PV) memiliki pengaruh signifikan pada

H7a: Habit (H) memiliki pengaruh signifikan pada behavioral intention (BI).

H7b: Habit $(\mathrm{H})$ memiliki pengaruh signifikan pada use behavior (UB).

$\mathrm{H} 8$ : Behavioral intention (BI) memiliki pengaruh signifikan pada use behavior (UB).

Penelitian ini juga khusus melihat bagaimana usia sebagai variabel moderator mempengaruhi dalam adopsi penggunaan $e$-commerce.

\section{METODE PENELITIAN}

Pemilihan metode ini dikarenakan penelitian merupakan penelitian eksplorasi dengan memiliki jenis data, kerangka pemikiran, algoritma yang digunakan, serta model evaluasi. Oleh karena itu, penelitian ini menggunakan Partial Least Square (PLS) Structural Equation Model (SEM).

Aturan pengambilan jumlah sampel minimum pada PLS-SEM terdapat dua ketentuan; pertama berdasarkan sepuluh kali jumlah indikator formatif atau sepuluh kali jumlah garis (path) penghubung setiap variabel laten didalam penelitian (Hair, Hult, Ringle, dan Sarstedt, 2015).

Pada penelitian ini menggunakan metode kuantitatif korelasional dengan model UTAUT In Consumer Context (UTAUT2) sebagai model utamanya. Pengambilan data menggunakan cara survey melaui pengisian kuesioner langsung oleh responden. Model UTAUT2 kemudian dimodifikasi melalui variabel moderasi yang mengasumsikan hanya ada pengaruh dari usia dalam adopsi terhadap e-commerce.

Data dikumpulkan dengan menggunakan teknik purposive sampling dimana pengambilan sample responden berdasarkan kriteria yang telah ditentukan.

\subsection{Metode Pengolahan Data}

Pengolahan data menggunakan teknik Structural Equation Model (SEM) dengan menggunakan perangkat lunak Smart-PLS 3.2.8 untuk menggambarkan model visualisasi hubungan variabel secara jelas (Hair et al., 2015).

\subsection{Populasi dan Sampel}

Populasi penelitian ini merupakan konsumen produk UMKM generasi milenial di Kota Subang 
yang sudah melakukan pembelian produk menggunakan internet (belanja online). Mengingat jumlah populasi banyak dan terkendala waktu penelitian sehingga dilakukanlah teknik judgement sampling.

Teknik judgement sampling dipakai pada penelitian ini dikarenakan pengambilan sampel berdasarkan pada penilaian terhadap kriteria anggota sampel dengan menyesuaikan maksud dari penelitian. Kriteria yang diterapkan pada pemilihan sampel penelitian ini diantaranya:

1. Responden melakukan kegiatan belanja online melalui internet minimal satu kali.

2. Responden yang berusia antara 15-35 tahun.

Shingga penentuan jumlah sampel pada penelitian ini menyesuaikan dengan kriteria ideal besaran sampel dengan pemodelan SEM sebesar 100-200 sampel dan minimal absolut 50 sampel ataupun besaran sampel minimal sebesar 5-10 dikali variabel indikator dari semua variabel laten.

Berdasarkan pendekatan minimal absolut pada penelitian ini diambil sebesar 100 yang didapatkan dari 10 jalur dikali 10. Sampel yang berhasil dikumpulkan sebanyak 150 sampel.

\subsection{Instrumen yang Digunakan}

Instrumen penelitian ini ditambahkan dari lima variabel UTAUT yaitu (1) performance expectancy, (2) effort expectancy, (3) social influence, (4) faciliting condition, dan (5) behavioral intention . Tiga variabel tambahan yaitu variabel UTAUT2 diantaranya (1) hedonic motivation, (2) price value dan (3) habit serta Variabel Moderator Usia (U).

Pada setiap item penelitian ini diukur melalui Skala Likert dengan rentang nilai satu yang berarti Sangat Tidak Setuju dan paling tinggi dengan nilai lima yang berarti Sangat Tidak Setuju.

\section{HASIL DAN PEMBAHASAN}

\subsection{HASIL}

Deskripsi responden dijelaskan agar bisa mengetahui karakteristik responden dalam penelitian ini. Data tersebut dijabarkan mulai dari jenis kelamin, usia, pengalaman berbelanja online pada $e$ commerce pada Tabel 1.

Tabel 1. Karakteristik Responden

\begin{tabular}{lll}
\hline & Kategori & Jumlah \\
\hline \multirow{2}{*}{ Jenis kelamin } & Pria & 48 \\
& Wanita & 102 \\
\multirow{2}{*}{ Usia } & 15-24 Tahun & 137 \\
Pengalaman & 25-34 Tahun & 13 \\
Belanja Online & Setahun & 38 \\
& Dua tahun & 37 \\
\hline
\end{tabular}

Pada penelitian ini didapatkan responden dengan didominasi wanita berusia 15-24 tahun dan sudah memiliki pengalaman belanja online setahun.

\subsubsection{Pengukuran Model}

Pengukuran model dipakai untuk evaluasi data dalam penentuan validitas dan reliabilitas data. Hubungan konstruk dengan setiap indikator penelitian ini bersifat model pengukuran reflektif. Pada pengukuran model reflektif ada dua pengujian validitas, yaitu pengujian validitas konvergen dan pengujian validitas diskriminan (Sofyani, 2015).

\subsubsection{Pengujian Validitas Konvergen}

Pengujian validitas konvergen didapatkan melalui hasil nilai Faktor loading (outer loadings), Composite Reliability $>$ (lebih besar dari) 0,70 dan parameter Average Variance Extracted (AVE) 0,50. Pada Tabel 2 dan Gambar 1, maka data penelitian

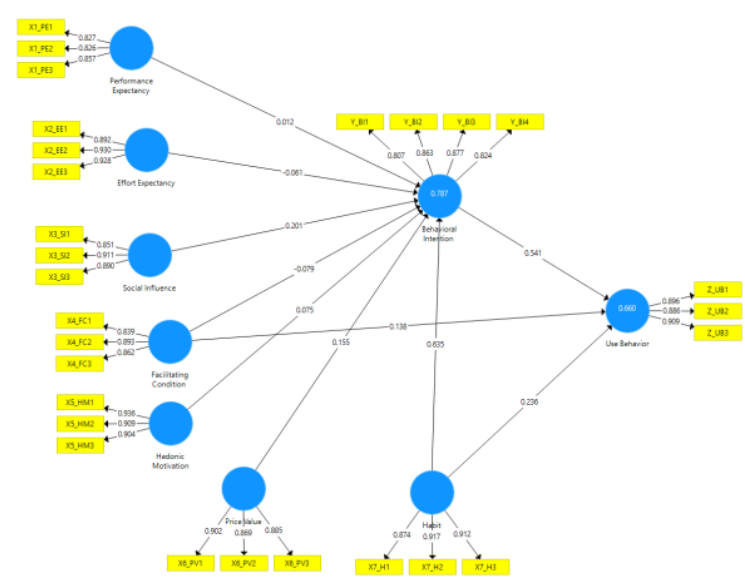

dinyatakan valid outer loading $>0,70$.

Gambar 1. Hasil Pengujian Outer Loadings

\subsubsection{Pengujian Validitas Diskriminan}

Pengujian validiatas diskriminan menggunakan beberapa item yang dijadikan sebagai patokan untuk parameter pengujian yaitu nilai akar AVE dan cross loading melebihi dari nilai 0,70 dan pada nilai cross loading pada indikator konstruk lebih tinggi dari nilai cross loading konstruk pada konstruk lain.

Pengujian reliabilitas menggunakan parameter nilai cronbach's alpha dan composite reliability memiliki nilai yang lebih besar dari 0,70.

\subsubsection{Hasil Pengujian}

Hasil dari pengolahan data menggunakan aplikasi Smart PLS 3.2.8 dilakukan dengan pengujian path coefficient, coefficient of determination dan variabel usia. Hasil pengujian disajikan pada Gambar 2.

\subsubsection{Uji Path Coefficient}

Pada aturan baku tentang keputusan terhadap didukungnya suatu hipotesis penelitian apabila; pertama arah hubungan variabel yang ditunjukkan dengan nilai original sample sejalan dengan 
hipotesis yang diajukan. Kedua, apabila nilai $\mathrm{t}$ statistik lebih dari 1,96 serta probability value kurang dari 0,05 .

Tabel 2. Hasil Pengujian Validitas dan Reliabilitas

\begin{tabular}{|c|c|c|c|c|}
\hline $\begin{array}{c}\text { Variabel } \\
\text { Laten }\end{array}$ & Indikator & $\begin{array}{c}\text { Outer } \\
\text { Loadings }\end{array}$ & $\begin{array}{l}\text { Composite } \\
\text { Reliability }\end{array}$ & AVE \\
\hline Performance & X1_PE1 & 0,827 & \multirow{3}{*}{0,908} & \multirow{3}{*}{0,711} \\
\hline \multirow{2}{*}{$\begin{array}{c}\text { Expectancy } \\
(\mathrm{PE})\end{array}$} & X1_PE2 & 0,826 & & \\
\hline & X1_PE3 & 0,857 & & \\
\hline Effort & X2_EE1 & 0,892 & \multirow{3}{*}{0,941} & \multirow{3}{*}{0,841} \\
\hline \multirow{2}{*}{$\begin{array}{c}\text { Expectancy } \\
\text { (EE) }\end{array}$} & X2_EE2 & 0,930 & & \\
\hline & X2_EE3 & 0,928 & & \\
\hline \multirow{3}{*}{$\begin{array}{l}\text { Social } \\
\text { Influence } \\
\text { (SI) }\end{array}$} & X3_SI1 & 0,851 & \multirow{3}{*}{0,899} & \multirow{3}{*}{0,748} \\
\hline & X3_SI2 & 0,911 & & \\
\hline & X3_SI3 & 0,890 & & \\
\hline \multirow{3}{*}{$\begin{array}{c}\text { Facilitating } \\
\text { Condition } \\
(\mathrm{FC})\end{array}$} & X4_FC1 & 0,839 & \multirow{3}{*}{0,928} & \multirow{3}{*}{0,812} \\
\hline & X4_FC2 & 0,893 & & \\
\hline & X4_FC3 & 0,862 & & \\
\hline \multirow{3}{*}{$\begin{array}{c}\text { Hedonic } \\
\text { Motivation } \\
\text { (HM) }\end{array}$} & X5_HM1 & 0,936 & \multirow{3}{*}{0,940} & \multirow{3}{*}{0,840} \\
\hline & X5_HM2 & 0,909 & & \\
\hline & X5_HM3 & 0,904 & & \\
\hline \multirow{3}{*}{$\begin{array}{c}\text { Price Value } \\
\text { (PV) }\end{array}$} & X6_PV1 & 0,902 & \multirow{3}{*}{0,875} & \multirow{3}{*}{0,700} \\
\hline & X6_PV2 & 0,869 & & \\
\hline & X6_PV3 & 0,885 & & \\
\hline \multirow{3}{*}{$\begin{array}{l}\text { Habit } \\
(\mathrm{H})\end{array}$} & X7_H1 & 0,874 & \multirow{3}{*}{0,916} & \multirow{3}{*}{0,784} \\
\hline & X7_H2 & 0,917 & & \\
\hline & X7_H3 & 0,912 & & \\
\hline \multirow{4}{*}{$\begin{array}{l}\text { Behavioral } \\
\text { Intention } \\
\text { (BI) }\end{array}$} & Y_BI1 & 0,807 & \multirow{4}{*}{0,915} & \multirow{4}{*}{0,782} \\
\hline & Y_BI2 & 0,863 & & \\
\hline & Y_BI3 & 0,877 & & \\
\hline & Y_BI4 & 0,824 & & \\
\hline Use & Z_UB1 & 0,896 & \multirow{3}{*}{0,925} & \multirow{3}{*}{0,805} \\
\hline \multirow{2}{*}{$\begin{array}{l}\text { Behavior } \\
\text { (UB) }\end{array}$} & Z_UB2 & 0,886 & & \\
\hline & Z_UB3 & 0,909 & & \\
\hline
\end{tabular}

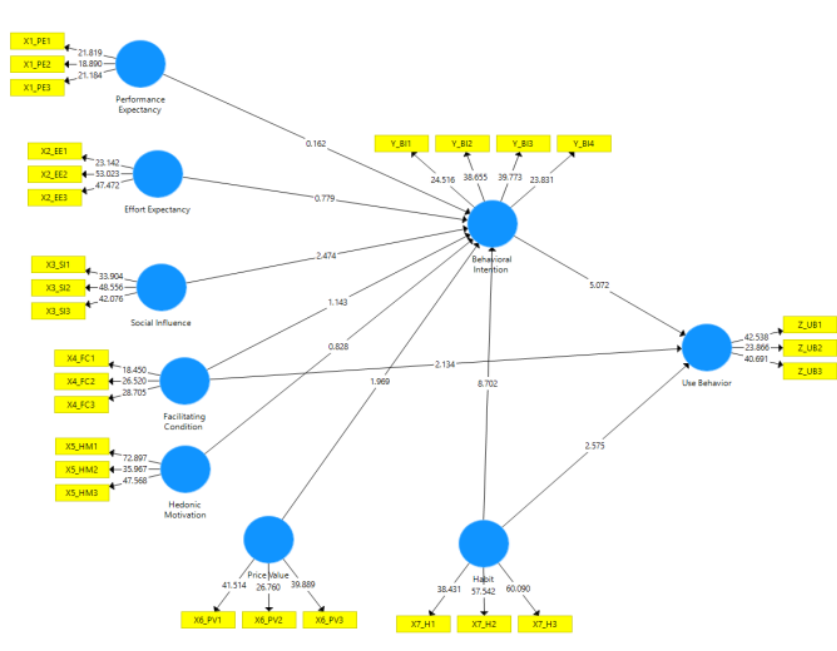

Gambar 2. Hasil Pengujian Path Coefficient
Tabel 3. Evaluasi Inner Model

\begin{tabular}{cccccc}
\multicolumn{6}{c}{ Tabel 3. Evaluasi Inner Model } \\
\hline Hipotesis & $\begin{array}{c}\text { Original } \\
\text { Sample }\end{array}$ & $\begin{array}{c}\text { Sample } \\
\text { Mean }\end{array}$ & STDEV & $\begin{array}{c}\mathrm{T} \\
\text { Statistics }\end{array}$ & $\begin{array}{c}\mathrm{P} \\
\text { Values }\end{array}$ \\
\hline BI > UB & 0,54 & 0,52 & 0,11 & 5,07 & 0,00 \\
EE $>$ BI & $-0,06$ & $-0,06$ & 0,08 & 0,78 & 0,44 \\
FC > BI & $-0,08$ & $-0,08$ & 0,07 & 1,14 & 0,25 \\
FC $>$ UB & 0,14 & 0,15 & 0,06 & 2,13 & 0,03 \\
HB $>$ BI & 0,63 & 0,63 & 0,08 & 8,70 & 0,00 \\
HB $>$ UB & 0,24 & 0,25 & 0,09 & 2,57 & 0,01 \\
HM $>$ BI & 0,07 & 0,06 & 0,09 & 0,83 & 0,41 \\
PE > BI & 0,01 & 0,02 & 0,07 & 0,16 & 0,87 \\
PV > BI & 0,15 & 0,16 & 0,08 & 1,97 & 0,05 \\
SI > BI & 0,20 & 0,21 & 0,081 & 2,47 & 0,01 \\
\hline
\end{tabular}

Pada Tabel 3 terlihat bahwa untuk hipotesis H3, H4b, H7a, H7b dan H8 dapat diterima karena memenuhi kriteria. Pada penyajian Tabel 4 dapat ditarik kesimpulan bahwa ada pengaruh signifikan dari social influence dan habit terhadap behavioral intenion. Selain itu juga dinyatakan ada pengaruh signifikan pada facilitating condition, habit dan behavioral intention terhadap use behavior.

\subsubsection{Uji Coefficient of Determination}

Hasil pengujian menyajikan simpulan bahwa varian dari setiap variabel endogen yang mengacu pada nilappi batas pengukuran 0,67 menunjukkan kuat,. Pada nilai 0,33 merupakan moderat, dan Pada nilai 0,19 ataupun lebih rendah adalah tingkat varian lemah (Hair et al., 2015). Tabel 4 menyajikan hasil perhitungan R-square.

\begin{tabular}{cc}
\multicolumn{2}{c}{ Tabel 4 Nilai R Square. } \\
\hline & R Square \\
\hline Behavioral Intention & 0,787 \\
Use Behavior & 0,660 \\
\hline
\end{tabular}

Berdasarkan Tabel 4 diatas diketahui nilai pada kontruk Behavioral Intention adalah sebesar 0,787 atau dibulatkan menjadi 0,79 menunjukan bahwa Behavioral Intention dipengaruhi sebesar $78 \%$ oleh $P E$, EE, SI, FC, HM, PV, dan H, sedangkan sisanya sebesar $22 \%$ dipengaruhi oleh faktor lain.

Pada kontruk UB, nilai nya adalah 0,660 atau dibulatkan menjadi 0,66 menunjukan bahwa UB dipengaruhi sebesar $66 \%$ oleh $\mathrm{BI}, \mathrm{FC}$ dan $\mathrm{H}$. Sisanya $34 \%$ dipengaruhi oleh faktor lain.

\subsubsection{Usia sebagai Variabel Moderator}

Pada penelitian ini didominasi usia 15-24 tahun yang menunjukkan bahwa pada rentang usia ini telah terbentuk kebiasaan dalam adopsi $e$ commerce menjadikan konsumen milenial ini potensial dalam pengulangan kegiatan belanja online membeli produk UMKM di e-commerce seperti shopee.co.id. 


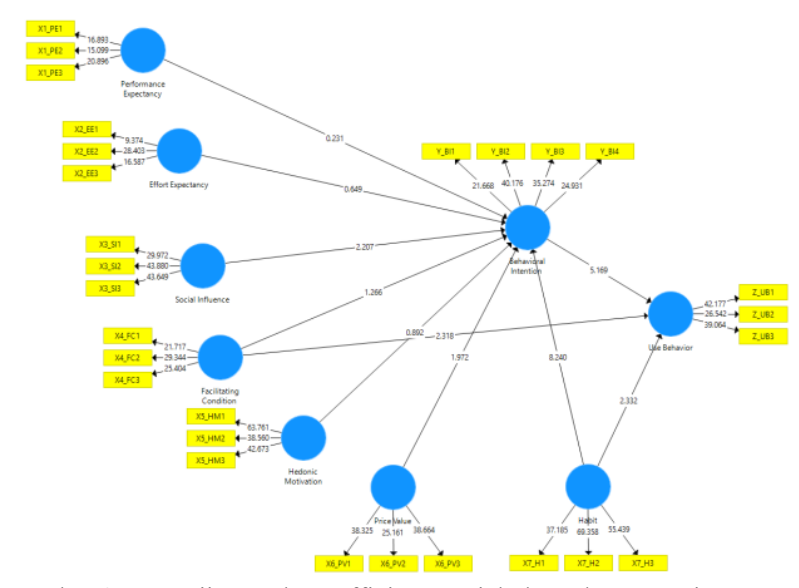

Gambar 3. Pengujian Path Coefficient Variabel Moderator Usia

\begin{tabular}{cccccc}
\multicolumn{6}{c}{ Tabel 5. Evaluasi Inner Model } \\
\hline $\begin{array}{c}\text { Hipotesi } \\
\text { s }\end{array}$ & $\begin{array}{c}\text { Origina } \\
\text { l } \\
\text { Sample }\end{array}$ & $\begin{array}{c}\text { Sampl } \\
\text { e } \\
\text { Mean }\end{array}$ & $\begin{array}{c}\text { STDE } \\
\text { V }\end{array}$ & $\begin{array}{c}\text { T } \\
\text { Statistic } \\
\text { s }\end{array}$ & $\begin{array}{c}\text { P } \\
\text { Values }\end{array}$ \\
\hline BI $>$ UB & 0,53 & 0,53 & 0,10 & 5,17 & 0,00 \\
EE $>$ BI & $-0,06$ & $-0,05$ & 0,09 & 0,65 & 0,52 \\
FC $>$ BI & $-0,10$ & $-0,10$ & 0,08 & 1,26 & 0,21 \\
FC $>$ UB & 0,15 & 0,16 & 0,06 & 2,32 & 0,02 \\
HB $>$ BI & 0,62 & 0,63 & 0,07 & 8,24 & 0,00 \\
HB $>$ UB & 0,24 & 0,23 & 0,10 & 2,33 & 0,02 \\
HM $>$ BI & 0,10 & 0,09 & 0,11 & 0,89 & 0,37 \\
PE $>$ BI & $-0,02$ & $-0,02$ & 0,08 & 0,23 & 0,82 \\
PV $>$ BI & 0,17 & 0,16 & 0,08 & 1,97 & 0,05 \\
SI $>$ BI & 0,20 & 0,20 & 0,09 & 2,21 & 0,03 \\
\hline
\end{tabular}

Pada Gambar 3 dan Tabel 5 menunjukkan bahwa hipotesis $\mathrm{H} 3, \mathrm{H} 4 \mathrm{~b}, \mathrm{H} 7 \mathrm{a}, \mathrm{H} 7 \mathrm{~b}$ dan $\mathrm{H} 8$ dapat diterima karena memenuhi kriteria sesuai tabel 5 diatas.

Tabel 5 menyatakan ada pengaruh signifikan dari efek moderasi usia yaitu terdapat pengaruh positif dan signifikan social influence (SI) dan habit (H) terhadap behavioral intenion (BI). Selain itu terdapat pengaruh signifikan facilitating condition (FC), habit $(\mathrm{H})$ dan behavioral intention (BI) terhadap use behavior.

\subsection{PEMBAHASAN}

H3: Adanya pengaruh positif dan signifikan social influence (SI) terhadap behavioral intenion (BI)

Hipotesis ini didukung karena nilai T Statistik yaitu 2,47. Nilai ini melebihi standar yaitu 1,96. Pada nilai $\mathrm{P}$ Value sebesar 0,01 , dapat diterima karena nilainya kurang dari 0,05 . Penilaian tersebut menjelaskan konsumen milenial mendapatkan pengaruh dari lingkumgan sekitarnya berupa srekomendasi dan dorongan (Megadewandanu, Suyoto, \& Pranowo, 2017) untuk melakukan kegiatan belanja online. Hal ini sejalan dengan beberapa penelitian sebelumnya yaitu pengaruh media sosial menjadi pengaruh yang signifikan Kamal \& Azis (2015), Putra \& Ariyanti (2017) dan (Piarna \& Ferdi, 2018) .

H4b: Adanya pengaruh positif dan signifikan facilitating condition (FC) terhadap use behavior (UB).

Hipotesis ini didukung karena nilai $\mathrm{T}$ Statistik yaitu 2,13. Nilai ini melebihi standar yaitu 1,96. Pada nilai $\mathrm{P}$ Value sebesar 0,03 , dapat diterima karena nilainya kurang dari 0,05 . Hasil penilaian tersebut menunjukkan bahwa fasilitas pendukung seperti handphone dan kuota internet Kamal \& Azis (2015) dan Piarna \& Ferdi (2018) dalam melakukan kegiatan belanja online berpengaruh signifikan bagi konsumen milenial.

\section{H7a: Adanya pengaruh positif dan signifikan} habit (H) terhadap behavioral intention (BI).

Hipotesis ini didukung karena nilai T Statistik yaitu 8,70. Nilai ini melebihi standar yaitu 1,96. Pada nilai $\mathrm{P}$ Value sebesar 0,00 , dapat diterima karena nilainya kurang dari 0,05 . Habit yang menjadi kebiasaan konsumen milenial telah berpengaruh signifikan dalam niat berperilaku belanja online seperti pada penelitian Kamal \& Azis (2015), Megadewandanu et al., (2017).

\section{H7b: Adanya pengaruh positif dan signifikan} Habit (H) terhadap use behavior (UB).

Hipotesis ini didukung karena nilai T Statistik yaitu 2,57. Nilai ini melebihi standar yaitu 1,96. Pada nilai $\mathrm{P}$ Value sebesar 0,01, dapat diterima karena nilainya kurang dari 0,05 .

Hasil ini mengkonfirmasi bahwa konsumen milenial sudah terbiasa dalam menggunakan internet untuk belanja online dikarenakan mereka telah sejak dini mengenal internet sehingga mereka lebih mudah dalam adopsi teknologi belanja online seperti pada penelitian Kamal \& Azis (2015), Megadewandanu et al., (2017)

Dominasi kebiasaan komsumen milenial terhadap adopsi e-commerce ini menunjukkan bahwa pada konsumen generasi milenial telah terbentuk kebiasaan dalam menggunakan internet dalam kehidupan sehari-harinya. Kegiatan ini dilakukan secara berulang disebabkan karena faktor pengalaman terdahulu (Venkatesh et al., 2012).

H8: Adanya pengaruh positif dan signifikan pada behavioral intention (BI) terhadap use behavior (UB).

Hasil ini nilai T Statistik yaitu 2,47. Nilai ini melebihi standar yaitu 1,96. Pada nilai $\mathrm{P}$ Value sebesar 0,01, dapat diterima karena nilainya kurang dari 0,05. Konsumen milenial telah memiliki pengalaman menggunakan internet sehingga 
kegiatan belanja online menjadi sesuatu hal yang akan dilakukan secara berkelanjutan. Hal ini sejalan dengan penelitian Kamal \& Azis (2015), Megadewandanu et al., (2017) dan (Piarna \& Ferdi, 2018).

\section{Usia sebagai Variabel Moderator}

Pada penelitian ini juga mengkonfirmasi bahwa konsumen milenial yang beusia dibawah tiga puluh lima tahun dimana social influence dan Habit menjadi faktor konsumen milenial untuk mendorong behavioral intenion pada kegiatan belanja dengan menggunakan internet. Serta Facilitating condition dimana fasilitas internet yang mudah didapatkann mendorong konsumen milenilal untuk melakukan belanja online. Selain itu konsumen milenial memutuskan niat untuk melakukan belanja menggunakan internet. Hasil penelitian ini seperti halnya yang dilakukan oleh Ramdhani, Rachmawati, Sidiq, \& Prabowo (2017) dan (Budiarto, 2018).

\section{KESIMPULAN DAN SARAN}

\subsection{KESIMPULAN}

Hasil penelitian ini menunjukkan bahwa social influence dan habit menjadi variabel yang memiliki pengaruh positif dan signifikan pada behavioral intenion pada kegiatan belanja dengan menggunakan internet. Facilitating condition, habit dan behavioral intenion berpengaruh positif dan signifikan pada use behavior. Sedangkan untuk performance expectancy, effort expectancy, hedonic motivation, price value tidak memiliki pengaruh signifikan terhadap behavioral intention. Hasil ini bisa menjadi referensi pelaku UMKM untuk mengembangkan pemasaran dengan mengggunakan media sosial karena konsumen milenial memiliki fasilitas untuk mengakses internet dalam aktifitasnya serta mudah dipengaruhi oleh lingkungan sosialnya.

\subsection{Saran}

Penelitian ini bisa dijadikan penelitian lanjutan dengan objek konsumen produk UMKM dengan menggunakan metode UTAUT2 yang lebih luas lagi tidak hanya satu kecamatan saja. Selain itu, pada penelitian ini hanya berfokus pada moderasi usia, sehingga bisa dikembangkan lagi pengaruh dari moderas pengalaman dan gender. Ada faktor presepsi resiko yang menjadi salah satu kendala konsumen untuk menggunakan e-commerce yang perlu diteliti lebih lanjut.

\section{DAFTAR PUSTAKA}

Alvara Research Center. 2017. The Urban MiddleClass Millenials Indonesia. 40. [online] Tersedia melalui: <http://alvara-strategic.com> [Diakses 4 Desember 2018]
Association of Indonesian Internet Service Providers. 2017. Penetrasi \& Perilaku Pengguna Internet Indonesia 2017. Penetrasi Dan Perilaku Pengguna Internet Indonesia, 139. [online] Tersedia melalui: < https://web.kominfo.go.id/sites/default/files/La poran Survei APJII_2017_v1.3.pdf $>$ [Diakses 8 Desember 2018]

AZIZ, M. 2016. Akses Digital Generasi Milenial. [online] Tersedia melalui: < https://www.timesindonesia.co.id/read/136748 /20161116/112713/akses-digital-generasimilenial/> [Diakses 10 Desember 2018]

Bank Indonesia. 2015. Profil Bisnis Usaha Mikro, Kecil Dan Menengah (Umkm) Kerjasama Lppi Dengan Bank Indonesia Tahun 2015.

BRAM. 2017. UMKM: Para Pejuang Perang Ekonomi Bangsa. [online] Tersedia melalui: < https://www.pemoeda.co.id/blog/umkm> [Diakses 15 Desember 2018]

BUDIARTO, R. 2018. Analisis Faktor Adopsi Aplikasi Mobile Berdasarkan Pengalaman , Usia Dan Jenis Kelamin Menggunakan UTAUT2. 3(2), 114-126.

HAIR, J. F., HULT, G. T. M., RINGLE, C. M., \& SARSTEDT, M. 2015. A primer on partial least squares structural equation modeling (PLS-SEM). In International Journal of Research \& Method in Education (Vol. 38). https://doi.org/10.1080/1743727x.2015.10058 06

KAMAL, R. M., \& AZIS, E. 2015. Adopsi Teknologi Internet Oleh Konsumen UMKM Indonesia Untuk Berbelanja Online ( Studi Pada Situs Tokopedia.Com Tahun 2015 ). 2(3), 2451-2458.

Kemenpppa. 2017. Hari Kependudukan Dunia 2017: Masa Depan Demografi Indonesia Dan Keseimbangan Pertumbuhan Penduduk. [online] Tersedia melalui: < https:/www.kemenpppa.go.id/index.php/page/ $\mathrm{read} / 29 / 1445 /$ hari-kependudukan-dunia-2017masa-depan-demografi-indonesia-dankeseimbangan-pertumbuhan-penduduk $>$ [Diakses 8 Desember 2018]

MEGADEWANDANU, S., SUYOTO, \& PRANOWO. 2017. Exploring mobile wallet adoption in Indonesia using UTAUT2: An approach from consumer perspective. Proceedings - 2016 2nd International Conference on Science and TechnologyComputer, ICST 2016, 11-16. https://doi.org/10.1109/ICSTC.2016.7877340

PERTIWI, N. W. D. M. Y., \& ARIYANTO, D. 2017. Penerapan Model UTAUT2 Untuk Menjelaskan Minat Dan Perilaku Penggunaan Mobile Banking Di Kota Denpasar. 18, 1369 1397.

PIARNA, R., \& FERDI, F. (2018). Adopsi ECommerce Pada UMKM Di Kota Subang 
Menggunakan Model UTAUT. Jurnal Ilmiah Ilmu Dan Teknologi Rekayasa, 1 Nomor 2, 63.

PUTRA, G., \& ARIYANTI, M. 2017. Pengaruh Faktor-Faktor Dalam Modified Unified Theory of Acceptance and Use of Technology 2 (Utaut 2) Terhadap Niat Prospective Users Untuk Mengadopsi Home Digital Services Pt. Telkom Di Surabaya. Jurnal Manajemen Indonesia, 14(1), 59. https://doi.org/10.25124/jmi.v14i1.352

RAMDHANI, A. B., RACHMAWATI, I., SIDIQ, F., \& PRABOWO, A. 2017. Pengaruh Adopsi Teknologi Layanan Uang Elektronik Telkomsel Cash Menggunakan Pendekatan Utaut2 the Effect of Technology Adoption Electronic Money Services Telkomsel Cash Using UTAUT2. E-Proceeding of Management, 4(1), 53.

SAPUTRA, P. 2018. Orang Indonesia Paling Gemar Belanja Fesyen dan Wisata secara Online. Retrieved from https:/katadata.co.id/infografik/2018/02/07/or ang-indonesia-paling-gemar-belanja-fesyendan-wisata-secara-online

SOFYANI, H. 2015. Modul Praktik Partial Least Square ( PLS ). Jurnal UMY.

SULIANTA, F. 2012. Smart Online Marketer. Andi Offset.

VENKATESH, V., THONG, J. Y. L., \& XU, X. 2012. Consumer acceptance and use of information technology: Extending the unified theory of acceptance and use of technology. MIS Quarterly: Management Information Systems, 36(1), 157-178. https://doi.org/10.2307/41410412

WINARKO, B., \& MAHADEWI, L. 2013. Tinjauan Beberapa Model Teori Dasar Adopsi Teknologi Baru. Media Bisnis.

WONG, J. 2013. Internet Marketing For Beginners. PT. Elex Media Komputindo. 